Dissolved Low-Molecular Weight Thiol Concentrations from the U.S. GEOTRACES North Atlantic Ocean Zonal Transect

Gretchen J. Swarr ${ }^{1}$, Tristan Kading ${ }^{1 \dagger}$, Carl H. Lamborg ${ }^{1 t^{*}}$, Chad R. Hammerschmidt ${ }^{3}$ and Katlin L. Bowman ${ }^{3+}$

${ }^{1}$ Dept. of Marine Chemistry and Geochemistry, Woods Hole Oceanographic Institution, Woods Hole, MA 02543

${ }^{3}$ Dept. of Earth \& Environmental Sciences, Wright State University, Dayton, OH 45435

†now at University of Connecticut, Groton, CT 06540

thow at University of California, Santa Cruz, Santa Cruz, CA 95064

*clamborg@ucsc.edu

Prepared for submission to DSRI

\title{
Abstract
}

16 Low-molecular weight thiols, including cysteine and glutathione, are biomolecules involved

17 in a variety of metabolic pathways and act as important antioxidant and metal buffering agents.

18 In this last capacity, they represent a potential mechanism for modulating the bioavailability and

19 biogeochemistry of many trace elements in the ocean, particularly for chalcophilic elements

20 (e.g., $\mathrm{Cu}, \mathrm{Zn}, \mathrm{Cd}, \mathrm{Ag}$ and $\mathrm{Hg}$ ). For this reason, and in the context of the international

21 GEOTRACES program that seeks to understand the biogeochemistry of trace elements in the

22 ocean, we measured the concentration of individual dissolved low-molecular weight thiols

23 during the U.S. GEOTRACES North Atlantic Zonal Transect (USGNAZT). Only two thiols

24 were identified, cysteine and glutathione, in contrast to results from the northeast subarctic

25 Pacific Ocean, where the dipeptides glycine-cysteine and arginine-cysteine were also present and

$26 \gamma$-glutamylcysteine was dominant. Concentrations of cysteine and glutathione in the North

27 Atlantic Ocean were lower than in the Pacific and ranged from below detection $(\sim 0.01 \mathrm{nM})$ to

$280.61 \mathrm{nM}$ of cysteine and up to $1.0 \mathrm{nM}$ of glutathione, with cysteine generally more abundant than

29 glutathione. Vertical profiles of cysteine and glutathione were broadly consistent with their

30 biological production, being more abundant in surface water and usually below detection at 
31 depths greater than about $200 \mathrm{~m}$. Subsurface concentration maxima, often co-incident with the

32 deep chlorophyll maximum, were frequently observed but not universal. We conclude that

33 cysteine and glutathione do not make up significant portions of complexation capacity for $\mathrm{Cu}$

34 and $\mathrm{Zn}$ in the upper open ocean but could be important for $\mathrm{Cd}, \mathrm{Hg}$, and potentially other

35 chalcophiles. Extremely low concentrations of cysteine and glutathione in deep water suggest

36 that higher molecular-weight thiols are a more important ligand class for chalcophiles in that

37 portion of the ocean.

39 1. Introduction

40 Thiols (organic compounds possessing -SH functional groups) are molecules synthesized by

41 cells to defend against oxidative stress induced by the presence of reactive oxygen species (Ercal

42 et al., 2001; Rijstenbil, 2002; Sunda et al., 2002). Thiols may also decrease the toxicity of metals

43 by chelating them and thereby lowering intracellular free metal concentrations which agrees with

44 the observed increase in intracellular thiol concentrations in phytoplankton, plants, and fungi as a

45 result of elevated metal exposure (Ahner et al., 2002; Rijstenbil and Gerringa, 2002; Courbot et

46 al., 2004; Dupont and Ahner, 2005). More recently, the role of thiols as metal transporters has

47 received increased attention because many chalcophilic metals possess both micronutrient and

48 toxic properties for cells (e.g., Satoh et al., 2002; Schaefer and Morel, 2009; Semeniuk et al., 49 2015).

50 Dissolved thiols are found in measureable concentrations in lake, estuary, and ocean waters.

51 Dissolved thiol concentrations are below $10 \mathrm{nM}$ in open-ocean seawater but have been observed

52 to be greater than $10 \mathrm{nM}$ in regions of high productivity (Tang et al., 2000; Al-Farawati and van

53 den Berg, 2001; Laglera and van den Berg, 2003; Dupont et al., 2006). However, thiol 
54 concentrations greater than $500 \mathrm{nM}$ have been observed in regions where permanently sulfidic

55 conditions are present, such as the Black Sea (Mopper and Kieber, 1991) and sediment pore

56 waters (Chapman et al., 2009).

57 Many different biogenic thiol compounds are present in marine environments. Compound-

58 specific analyses of dissolved thiols have identified cysteine, glutathione, and $\gamma$-glutamylcysteine

59 as the most common low-molecular weight thiols in the natural waters studied (Mopper and

60 Kieber, 1991; Tang et al., 2000; Dupont et al., 2006; Hu et al., 2006). Other thiols, that are less

61 frequently observed in seawater, include the dipeptides cysteinyl-arginine and cysteinyl-

62 glutamine in the North Pacific (Dupont et al., 2006) and phytochelatins, which are oligomers of

63 glutathione, in coastal waters (Ahner et al., 1997; Tang et al., 2000). Cysteine-rich small

64 proteins, such as metallothioneins, are also commonly produced by algal cells (Ahner and Morel,

65 1995), but dissolved metallothioneins have yet to be detected in the ocean. The diversity of thiols

66 present in natural waters is likely greater than that already described, because unidentified thiol

67 compounds have been observed in chromatograms (e.g., Tang et al., 2000).

68 Thiol composition and concentration differences among regions of the ocean may be the

69 result of differences in plankton community, their metal exposures, and local environmental

70 factors that influence thiol fate in the water column (Ahner et al., 2002; Dupont and Ahner,

71 2005). Relevant to GEOTRACES is the implication that changes in plankton community

72 composition could affect chalcophilic metal biogeochemistry by controlling the biogenic thiol

73 assemblage that is produced. As the primary source of thiols is biogenic production, co-variation

74 between dissolved thiols and chlorophyll $a(\mathrm{Chl} a)$ concentrations might be expected and indeed

75 has been observed in the surface coastal ocean (Al-Farawati and van den Berg, 2001). However,

76 thiol concentrations were unrelated to $\mathrm{Chl} a$ in surface water from both the northwest Pacific and 
northwest Atlantic (Dupont et al., 2006; Kading, 2013), which suggests that the sinks (primarily

78 photo-oxidation and biological uptake) for thiols may be just as influential as biogenic

79 production in determining ambient concentrations, especially in oligotrophic surface waters and

80 at depths below the photic zone. For example, photochemical destruction of the thiol pool in the

81 surface ocean has been demonstrated to be on the order of hours (Flock et al., 1997; Winterbourn

82 and Metodiewa, 1999; Laglera and van den Berg, 2006; Moingt et al., 2010). Photochemical

83 decomposition in surface water is consistent with the observation of an increase in thiol

84 concentration from the sea surface to a maximum at the deep chlorophyll maximum, where

85 primary productivity is still active but light levels are lower (Dupont et al., 2006), and may even

86 imply that the time of day could influence vertical distributions of thiols. The decrease is also

87 consistent with biological uptake as cysteine has been observed to be taken up in varying degrees

88 by SAR11 and other $\alpha$-proteobacteria, which are thought to be the dominant heterotrophic

89 bacteria in the ocean (Kiene et al., 1999; Tripp et al., 2008). Thus, there are both physical and

90 biological controls on the sources and sinks of dissolved low-molecular weight thiols in the

91 ocean, and the controls are likely to interact in complex ways, giving rise to a variety of vertical

92 and horizontal profiles that could obscure correlations with tracers of productivity, such as Chl $a$.

93 Dissolved thiols have the potential to exist in both reduced (RS ${ }^{-}$) and oxidized (RSSR) forms,

94 which impacts their ability to complex metals. In addition to a relatively slow reaction rate with

95 molecular oxygen in oxic waters, oxidation of low-molecular weight thiols has been observed to

96 be catalyzed by $\mathrm{Cu}(\mathrm{II})$, superoxide, $\mathrm{H}_{2} \mathrm{O}_{2}$ and ultraviolet radiation (Winterbourn and Metodiewa,

97 1999; Rigo et al., 2004; Moingt et al., 2010). The presence of $\mathrm{Hg}$ and $\mathrm{Ag}$ at concentrations

98 comparable to those of thiols has been demonstrated to greatly reduce the rate of glutathione

99 oxidation presumably by strong complexation (Hsu-Kim, 2007). However, this is a situation 
100 unlikely to occur in nature as $\mathrm{Hg}$ and $\mathrm{Ag}$ are typically $100-1000 \times$ less abundant than glutathione.

101 A single measurement suggests that about half the dissolved thiols in the surface ocean are 102 reduced, with the remainder as oxidized dithiol (Dupont et al., 2006).

103 In an effort to better understand the fates of chalcophilic metals in the ocean and the 104 biogeochemistry of their ligands, we used seawater collected during the U.S. GEOTRACES 105 North Atlantic Zonal Transect (USGNAZT) to quantify compound-specific concentrations of as 106 many low-molecular weight thiols as we could identify and detect. While this kind of study has 107 been completed in the past (e.g., Dupont et al., 2006), we believe this to be the largest such 108 report of species-specific thiol concentrations in the ocean and the first to span an entire basin.

\section{2. Methods}

\section{$113 \quad 2.1$ Cruise track and sampling}

114 The cruise track for the U.S. GEOTRACES North Atlantic Zonal Transect (USGNAZT), 115 also referred to as GEOTRACES Atlantic 03 (GA03), is shown in Figure 1, and consisted of two 116 legs, both aboard the R/V Knorr. The first (KN199-4), beginning on 15 October 2010 from 117 Lisbon, Portugal occupied stations in the eastern North Atlantic stretching mostly meridionally 118 south to the Cape Verde Islands, where the leg was cut short by a mechanical problem on 4 119 November 2010. This leg included stations 9-12, which constituted a short zonal section through 120 a region of higher productivity associated with the Mauritanian Upwelling. An additional 121 component of Leg 1 were surface-only collections from an underway towed "fish" system 122 (Bruland et al., 2005) made during transit from Cape Verde to Charleston, South Carolina from 8 
123 to 26 November 2010 as the ship returned to the U.S. for repair. Leg 2 (KN204-1A \& B), from 2

124 November to 11 December 2011, occupied stations between Woods Hole, U.S. and Cape Verde.

125 This leg featured several closely spaced stations near the western continental margin, station

126 BATS (Bermuda Atlantic Time Series), and the TAG hydrothermal vent.

127 At each station, water samples for analysis of dissolved thiols were obtained from Niskin

128 bottles deployed from a rosette used to collect water for isotopic and non-contamination prone

129 trace elements analysis (the "ODF Rosette"). The rosette was outfitted with an on-board CTD

130 and triggered manually as electrochemical and depth data were received through a conducting

131 cable. On deck, water was filtered from the Niskin bottles by members of the scientific crew

132 through Acropak filters $(0.45 \mu \mathrm{m}$, polyethersulfone) into low-density polyethylene bottles (60

$133 \mathrm{~mL}$ ) that had been previously cleaned with $\mathrm{HCl}$ and rinsed with reagent-grade water (resistivity >

$13418 \mathrm{M} \Omega-\mathrm{cm})$. We refer to thiols in these samples as being "dissolved" but they should more

135 accurately be described as "filtered" because colloids and particles less than $0.45 \mu \mathrm{m}$ could have

136 passed the filter. Samples were frozen $\left(-20{ }^{\circ} \mathrm{C}\right)$ immediately, without further amendment, and

137 kept frozen until processing in the laboratory at WHOI. In this study, we made no effort to

138 preserve the oxidation state of the thiols, but rather make use of a method that reduces all thiols

139 prior to analysis. Therefore, the concentration of thiols present in seawater that is available to

140 participate in metal complexation will be some fraction of the value reported here. There has

141 been no work in seawater, to our knowledge, regarding the effects of freezing on the long-term

142 stability of low-molecular weight thiols. Thus, there is a possibility that some of our analytes

143 were oxidized beyond the formation of disulfide bonds (which our method addresses) to the

144 formation of sulfonates during storage. Such work should be performed to aid in further

145 validating our data. 


\subsection{Derivitization}

148 Before analysis, frozen seawater samples were thawed overnight in a refrigerator and

149 acidified to $15 \mathrm{mM}$ with methanesulfonic acid (MSA). Samples (50 mL) were derivatized and 150 analyzed according to the methods of Tang and colleagues (2003) with a few modifications 151 (Kading, 2013). Changes to the Tang protocol included use of tris(2-carboxyethyl)phosphine 152 (TCEP) as the reducing agent, and addition of the reducing agent after neutralization, rather than 153 before. Prior to derivitization, the $\mathrm{pH}$ of the samples was adjusted to between 4 and 5 with $6 \mathrm{M}$ $154 \mathrm{NaOH}$ and the thiols present in the sample were reduced by reaction with TCEP $(83 \mu \mathrm{L}$ of a 5 $155 \mathrm{mg} / \mathrm{mL}$ solution per $50 \mathrm{~mL}$ sample) at room temperature for 30 minutes. This results in an in156 sample concentration of TCEP of about $33.2 \mu \mathrm{M}$, which results in a TCEP/thiol ratio around

15710,000 . Samples were then buffered carefully to a $\mathrm{pH}$ of $\sim 8.5$ for optimal reaction kinetics by 158 addition of $2 \mathrm{M}$ boric acid, $0.8 \mathrm{M} \mathrm{NaOH}$, and $10 \mathrm{mM}$ EDTA solution. Thiol derivitization was 159 accomplished by the addition of $80 \mu \mathrm{L}$ of $10 \mathrm{mM}$ monobromobimane (mBBr) which was 160 allowed to react for 2 hours at $60{ }^{\circ} \mathrm{C}$. This recipe results in a nominal TCEP to $\mathrm{mBBr}$ ratio of 161 about 2 , well below the reductant/mBBr ratio limits suggested by Tang and colleagues $(<5.2)$. 162 We did detailed optimization experiments in seawater from Martha's Vineyard Sound (relatively 163 high thiol and $\mathrm{Cu}$ concentrations) and found the ratio of 0.8 to be optimal, but the higher ratio 164 gave better results for open ocean waters like those reported here. The reaction was terminated 165 (and the sample $\mathrm{pH}$ adjusted for column retention) with the addition of $800 \mu \mathrm{L}$ of $6 \mathrm{M}$ MSA. 166 Standards for calibration were prepared through addition of cysteine and glutathione to an 167 "average" seawater made by combining excess sample into $50 \mathrm{~mL}$ volumes that were then 168 derivatized and analyzed in the same way as samples. Similar to Tang et al. (2003), the $50 \mathrm{~mL}$ 
169 samples were passed through Waters Oasis HLV $3 \mathrm{cc}(60 \mathrm{mg})$ cartridges at less than $2 \mathrm{~mL} / \mathrm{min}$

170 and eluted with $1 \mathrm{~mL}$ of methanol into 2-mL amber vials. Methanol eluent was evaporated from

171 the vials overnight with air before derivatized thiols were dissolved in $1 \mathrm{~mL}$ of $15 \mathrm{mM}$ MSA for

172 analysis.

173

$174 \quad 2.3$ Analysis

175 Every standard and sample was analyzed with an Agilent 1200 series high performance

176 liquid chromatograph (HPLC). Sample aliquots of $100 \mu \mathrm{L}$ were injected onto a Waters

177 Spherisorb $5 \mu \mathrm{m}$ ODS2 $4.6 \times 250 \mathrm{~mm} \mathrm{C18}$ column with attached $4.6 \times 10 \mathrm{~mm}$ guard column at

$17830{ }^{\circ} \mathrm{C}$. The elution gradient started at $8 \%$ acetonitrile (mobile phase) and $92 \%$ water with $0.1 \%$

179 trifluoroacetic acid (TFA) at a flow rate of $1 \mathrm{~mL} /$ minute. The percentage of acetonitrile was

180 increased as follows: $8-10 \%$ from 1 to 13 minutes; $10-14 \%$ from 13 to 20 minutes; $14-16 \%$

181 from 20 to 24 minutes, $16-18 \%$ from 24 to 28 minutes, $18-24 \%$ from 28 to 35 minutes; $24-80 \%$

182 from 35 to 43 minutes, and from $80 \%$ back down to $8 \%$ from 43 to 47 minutes, followed by 15

183 minutes at $8 \%$ acetonitrile before the next sample was injected. The flow rate was increased to

$1841.3 \mathrm{~mL} / \mathrm{min}$ from 20 to 24 minutes and brought back down to $1 \mathrm{~mL} / \mathrm{min}$ from 24 to 28 minutes to

185 wash out the reagent peak (Tang et al., 2003). The individual derivitization products were

186 detected by fluorescence (Agilent FLD) with excitation and emission wavelengths of 394 and

$187470 \mathrm{~nm}$, respectively. This excitation/emission pair was deemed optimal after examining several

188 wavelength pairs and identifying the region of highest signal strength. Detection limits for

189 cysteine and glutathione were about $0.01 \mathrm{nM}$, but varied based on derivitization efficiency and

190 blanks each day. A typical chromatogram is shown in Figure 2. 
We determined retention times for cysteine, glutathione, $\gamma$-glutamylcysteine, arginylcysteine,

192 glycylcysteine, N-acetyl-cysteine, homocysteine, and phytochelatins 2-5 (PC2-5; noted in Figure

193 2) with standards, but identified only cysteine and glutathione in seawater samples. However,

194 there were several chromatogram peaks in samples that were not seen in blanks or corresponded

195 to thiols for which we had standards. The cumulative integrated area for these unidentified peaks

196 was greater than that of glutathione and cysteine, suggesting that a large fraction of the total thiol

197 concentration and metal complexing capacity in these waters was associated with compounds

198 that have not been characterized. The mBBr tag does not exclusively react with reduced thiols,

199 and has been observed to react with other functional groups as well (e.g., Fahey et al., 1980),

200 albeit at lower efficiencies than with thiols. Thus, some of the unidentified peaks could be non-

201 thiol-containing compounds as well as thiols.

202 Sixteen of the samples were run in duplicate to assess the reproducibility of this technique.

203 These duplicates had average relative standard deviations for cysteine and glutathione 204 concentrations of $34 \%$ and $43 \%$, respectively. In addition, an in-house seawater reference, made

205 from pooled extra water, was analyzed 9 times over the course of this work, and these analyses 206 had relative standard deviations of $28 \%$ and $31 \%$ for cysteine and glutathione analyses, 207 respectively. Thus, a conservative estimate of error might be $\pm 40 \%$.

\section{3. Results}

211 Vertical profiles of cysteine and glutathione concentrations are shown in Figures 3-7. The 212 maximum concentrations of cysteine and glutathione observed over the entire sampling 213 campaign were $0.61 \mathrm{nM}$ and $2.21 \mathrm{nM}$, respectively. The maximum measured cysteine 
214 concentration is lower than the $\sim 2 \mathrm{nM}$ maximum observed in the northeast Pacific Ocean

215 (Dupont et al., 2006), while the maximum glutathione concentration is similar between both

216 basins. At most stations, either surface or near-surface maxima decrease to concentrations below

217 detection at depths of 200-500 m below the surface.

218 The general range of concentrations observed along the sections agrees reasonably well with

219 expectations from prior studies. For example, Keil and Kirchman (1999) measured the

220 concentration of dissolved free amino acids (DFAA) in the northwest Atlantic Ocean in an

221 oceanographic setting comparable to our stations 2011-6 and 2011-8. They found DFAA

222 concentrations less than $10 \mathrm{nM}$ and with a similar vertical profile to that we observed for

223 cysteine and glutathione. As cysteine typically represents $0.5-2 \%$ by mole of amino acids in

224 proteins (e.g., Miseta and Csutora, 2000), we would therefore predict that cysteine

225 concentrations in Keil and Kirchman's DFAA pool would have been $<0.2 \mathrm{nM}$, which is within

226 the range measured in this study.

227 Two general profile types were observed for cysteine and glutathione in the North Atlantic

228 Ocean. The majority of the profiles displayed sub-surface maxima of cysteine and glutathione

229 concentrations (e.g., station 2010-10). For most of the profiles of this type, there was also a sub-

230 surface maxima for chlorophyll, but the thiol maxima were generally shallower than the peak in

231 Chl $a$. The remaining profiles showed little evidence of a subsurface peak, and instead had

232 maximum thiol concentrations at the surface. Surface maxima were observed almost exclusively

233 at the nearshore stations (stations 2010-9 through 2010-11; 2011-1 through 2011-6) and were

234 associated with Chl $a$ maxima that were broad and near the surface. These results suggest that

235 cysteine and glutathione were covariant, but thiol concentrations were not correlated with Chl $a$

$236\left(r^{2}=0.07\right.$ for cysteine, $r^{2}=0.06$ for glutathione $)$. This general trend of broad co-variation was 
237 usually seen for both cysteine and glutathione, but at some stations (2010-1, 2010-7 and 2010-

238 11) subsurface maxima were observed for cysteine, but not glutathione. Across the whole data

239 set, cysteine and glutathione concentrations were not well correlated with each other $(r=0.58)$,

240 but when observed on a station by station basis, about half the stations had $r>0.7$ between

241 cysteine and glutathione. The stations that had the greatest correlation coefficients between

242 cysteine and glutathione were not systematically distributed, and unrelated to either location,

243 local time of collection, or Chl $a$ distributions.

245 Figure 8 shows the concentration of cysteine and glutathione in surface waters $(<20 \mathrm{~m})$ from

246 both the 2010 and 2011 legs, including ad hoc surface water sampling from Cape Verde to

247 Charleston, South Carolina between the two official legs of the cruise. Concentrations of both

248 cysteine and glutathione were notably greater near the margins, as might be expected due to the

249 higher levels of primary productivity associated with these waters compared to the gyre. The

250 cysteine to glutathione ratio was near unity and fairly uniform across most of the basin.

251 However, the cysteine to glutathione ratio increased on the margins and was greater on the

252 western than eastern margin. The differences of cysteine to glutathione ratios may reflect

253 differences in plankton community composition, differences in the oxidative stresses

254 experienced by plankton, or perhaps differences in the photo-reactivity of these two compounds.

256 There is evidence from other studies for photodegradation of thiols (Moffett, 1995; Dupont et

257 al., 2004; Laglera and van den Berg, 2006), which suggests that there is a potential for a

258 sampling time-of-day bias on the observed thiol concentrations for samples from the photic zone,

259 which if strong enough might either present false trends or hide real trends across the basin 
260 depending on the time of day of the sampling. We examined our shallowest samples for any

261 evidence of bias by plotting their concentrations as a function of local sampling time (Figure 9).

262 Some of the samples collected at mid-day had a slightly lower concentration than those collected

263 at other times, but no clear trend was observed (i.e., no significant correlation with hours

264 before/since noon). Thus, it would appear that photodegradation of cysteine and glutathione is

265 less important than other sources of variability in determining the distribution of these 266 compounds in surface seawater.

268 The TAG hydrothermal field station was the only location where a measurable concentration 269 of either cysteine or glutathione was observed at a depth below $500 \mathrm{~m}$. At that station, a single 270 sample contained a measurable concentration of cysteine from a depth where a plume of 271 hydrothermally impacted water was known to exist (e.g., Fitzsimmons et al., 2015; Hatta et al., 272 2015; Jenkins et al., 2015; Lam et al., 2015; Measures et al., 2015; Sedwick et al., 2015). 273 Interestingly, this particular plume was not enriched in $\mathrm{Cu}$ (Jacquot and Moffett, 2015), and the 274 cysteine enrichment was confined to a single depth at the core of the plume, while other 275 parameters were enriched at several depths above and below the single point for cysteine. 276 Submarine hydrothermal vent plumes are known to be enriched in reduced sulfur, but usually as 277 sulfides. However, Reeves and colleagues (2014) noted that hydrothermal fluids can be highly 278 enriched in methanethiol, but did not report anomalously high concentrations of either cysteine 279 or glutathione.

\section{4. Discussion}


Concentrations of cysteine and glutathione in the North Atlantic Ocean are relatively low when compared to the concentration of chalcophile ligands, as determined through competitive copper ligand titrations along this section (Jacquot and Moffett, 2015) or in general (e.g.,

287 Bruland and Lohan, 2004; Buck and Bruland, 2005; Bundy et al., 2013; Heller and Croot, 2015).

288 This suggests that the low-molecular weight thiols determined in this study are only a small 289 fraction of the whole potential complexation capacity for $\mathrm{Cu}$ and, likely, most other chalcophiles 290 as well. Though the low-molecular weight thiols might not be a large fraction of the $\mathrm{Cu}$ ligand 291 pool, they might be important if their binding strengths are high. There is some controversy here 292 as IUPAC values for cysteine and the so-called L1 Cu ligand class appear to be similar in this 293 regard when allowances are made for the differences of thermodynamic and conditional data 294 (Berthon, 1995), while more recently Walsh and Ahner (2013) have suggested that the K values 295 (and the K' values implied by them) compiled by Berthon (1995) are substantially too large, 296 offering $\mathrm{K}^{\prime}$ values closer to $10^{11.3} \mathrm{M}^{-1}$ for $\mathrm{Cu}(\mathrm{I})$-cysteine and $10^{11.9} \mathrm{M}^{-1}$ for $\mathrm{Cu}(\mathrm{I})$-glutathione. 297 Given the sub-nanomolar concentrations of both thiols observed in this study, the three orders of 298 magnitude difference in $\mathrm{K}^{\prime}$ values controls whether cysteine and glutathione complexes are a 299 dominant $\mathrm{Cu}$ species in the open ocean or not. If the more recent and lower K' values are more 300 accurate, then we must come to the same conclusion as Walsh and Ahner (2013): low-molecular 301 weight thiols do not have an important role in $\mathrm{Cu}$ complexation in the dissolved phase of the 302 open ocean. The case of $\mathrm{Zn}$ mirrors that of $\mathrm{Cu}$ as well, with Walsh and Ahner's (2013) K' values 303 substantially less than those determined from titrations (e.g., Ellwood and Van den Berg, 2000; 304 Lohan et al., 2005), leading to the same conclusion that the observed concentrations of cysteine 305 and glutathione have little influence on $\mathrm{Zn}$ speciation. 
The importance of LMW thiols for Cd may be quite similar to that of $\mathrm{Cu}$. Bruland (1992)

307 documented Cd ligand concentrations in the open North Pacific Ocean that were around 0.1 nM

308 and confined to the upper $200 \mathrm{~m}$, in much the same way that we observed cysteine and 309 glutathione distributed vertically in the North Atlantic Ocean. Furthermore, the K' for this ligand

310 class with $\mathrm{Cd}$ was measured to be around $10^{12.0} \mathrm{M}^{-1}$ (Bruland, 1992), which is quite similar to

311 values reported for 1:1 Cd complexes with cysteine, again, accounting for activity differences

312 (Berthon, 1995). However, Walsh and Ahner (2013) also noted major discrepancies between

313 their results and that of IUPAC with regard to Cd ligands, and this is supported by the work of

314 others as well (e.g., Chekmeneva et al., 2011; Baars et al., 2014). Thus, cysteine and glutathione

315 are likely too weak to make up a significant fraction of $\mathrm{Cd}$ speciation in the dissolved phase of

316 the open ocean, similar to $\mathrm{Cu}$ and $\mathrm{Zn}$.

317 Prominence in speciation may not be the final word on the importance of LMW thiols and 318 the biogeochemistry of $\mathrm{Cu}, \mathrm{Zn}$ and $\mathrm{Cd}$. For example, Semeniuk and colleagues (2015) recently 319 conducted radio-copper uptake experiments from seawater by phytoplankton and bacteria in the 320 presence of natural $\mathrm{Cu}$-complexing ligands as well as in seawater amended with naturally 321 occurring and synthetic ligands. They observed dramatically higher rates of $\mathrm{Cu}$ uptake when 322 either cysteine, glutathione, or another "weak" ligand (bathocuproinedisulfonic acid) was added, 323 even though $\mathrm{Cu}$ complexes with these ligands should make up only a tiny fraction of total $\mathrm{Cu}$.

324 Thus, while measured equilibrium constants discourage the view that cysteine and glutathione 325 account for a significant fraction of dissolved $\mathrm{Cu}$ complexation in the ocean, these low-molecular 326 weight "weak" ligands may have an important role in the marine biogeochemistry of $\mathrm{Cu}$. The 327 same might be true as well for $\mathrm{Cu}$ photochemistry, where the tiny pool of cysteine-bound $\mathrm{Cu}$ 328 could represent an important control on redox cycling for that metal (Leal and Van den Berg, 
1998). Weak ligand facilitation of uptake has also been suggested for $\mathrm{Zn}$ (Aristilde et al., 2012)

330 and Fe (Croot and Heller, 2012).

4.2 The Importance for $\mathrm{Hg}$ and Ag speciation

Organic ligand concentrations and affinities for $\mathrm{Hg}$ have been measured in open ocean

334 seawater in only one case of which we are aware (Lamborg et al., 2004). In that instance, ligand

335 concentrations were sub-nanomolar and conditional affinities were $\sim 10^{23} \mathrm{M}^{-1}$, which is similar to

336 tabulated values for $\mathrm{Hg}$ complexation with cysteine (Berthon, 1995), with conditional

337 corrections. The ranges of stability constants in the IUPAC compilation for $\mathrm{Hg}$ with cysteine and

338 glutathione are very large, however, so the most that can be said is that our field data is

339 consistent with the hypothesis that low-molecular weight thiols dominate Hg speciation. Refined

340 laboratory data on thiol affinities for $\mathrm{Hg}$ are needed to further test this view.

341 One of our interests in determining thiol concentrations in open-ocean seawater was to test

342 whether these ligands could exert any control on bioavailability that might modulate $\mathrm{Hg}$ (II)

343 conversion into monomethylmercury $\left(\mathrm{CH}_{3} \mathrm{Hg}^{+}\right)$in the ocean, as has been observed during

344 incubations of cultured methylating and non-methylating bacteria (Schaefer and Morel, 2009;

345 Szczuka et al., 2015). As noted, cysteine and glutathione concentrations reach their maxima in

346 waters shallower than $200 \mathrm{~m}$, and often near the surface, which is generally not the case for

347 vertical distributions of $\mathrm{CH}_{3} \mathrm{Hg}^{+}$and certainly not on these sections of the North Atlantic Ocean

348 (Bowman et al., 2015). While the lack of correlation between vertical distributions of cysteine,

349 glutathione, and $\mathrm{CH}_{3} \mathrm{Hg}^{+}$distributions does not mean that these low-molecular weight thiols play

350 no role in open-ocean $\mathrm{Hg}$ methylation, it is clear that, at present, the distribution of the thiols

351 offers no help in predicting the distribution of $\mathrm{CH}_{3} \mathrm{Hg}^{+}$. 
There is not enough data to assess how important thiols like cysteine and glutathione might

353 be for complexation of Ag in the open ocean. Strong complexation by organic ligands is known

354 to occur for Ag, as Ndung'u and colleagues demonstrated that UV digestion of water samples

355 was necessary to liberate the Ag prior to further analysis (Ndung'u et al., 2006). However, no

356 ligand titrations for $\mathrm{Ag}$ have been performed in seawater to our knowledge, preventing

357 comparison of our data to ambient ligand properties.

\subsection{First-order modeling of thiol distributions}

The general shape of cysteine and glutathione vertical profiles would appear to be consistent

361 with a model consisting of production at either the surface or chlorophyll maximum by 362 phytoplankton, and then dispersion downward and loss to either decomposition or biological 363 uptake. However, it is interesting that measurable concentrations of cysteine and glutathione 364 were observed substantially below the surface and chlorophyll maximum, which begs the 365 question of how these profiles could arise and be sustained. In this section, we developed a 366 simple model to test whether this view is a plausible explanation of thiol distributions in the 367 North Atlantic. The downward dispersion of dissolved thiols could take two forms, either 368 vertical eddy-driven diffusion or particle sinking coupled to remineralization. Thus as a first step 369 and to simplify further modeling, we examined whether particle sinking or vertical diffusion 370 could be determined to be more important in the case of thiols. The downward flux of dissolved 371 thiols associated with vertical diffusion can be modeled as:

372

$$
F_{d i f f}=-K_{z} \frac{\partial C}{\partial z}
$$


374 where $F$ is the flux (mole $\left.\mathrm{m}^{-2} \mathrm{~d}^{-1}\right), K_{z}$ is the vertical eddy diffusivity $\left(\mathrm{m}^{2} \mathrm{~d}^{-1}\right), C$ is the 375 concentration of dissolved thiol $\left(\right.$ mole $\left.\mathrm{m}^{-3}\right)$ and $z$ is depth (m). Typical $K_{z}$ values are on the order 376 of $10^{-5}-10^{-2} \mathrm{~m}^{2} \mathrm{~s}^{-1}$ (i.e., $1-1000 \mathrm{~m}^{2} \mathrm{~d}^{-1}$ ) in this region of the ocean (Ledwell et al., 1993).

377 Because the vertical gradient in thiol concentrations near the surface is on the order of 1 nmole $378 \mathrm{~m}^{-4}$, the model suggests a range of possible values for $F_{\text {diff }}$ of $1-1000 \mathrm{nmole} \mathrm{m}^{-2} \mathrm{~d}^{-1}$.

379 The downward flux of thiols associated with particle sinking (ignoring rates of 380 remineralization for the moment to provide an upper end estimate) can be modeled as:

$$
F_{\text {sink }}=w C_{p}
$$

383 where $w$ is the vertical sinking rate $\left(\mathrm{m} \mathrm{d}^{-1}\right)$ and $C_{p}$ is the concentration of particulate thiols (mole $384 \mathrm{~m}^{-3}$ ). Values of $w$ have been observed to range widely from about 20 to over $1000 \mathrm{~m} \mathrm{~d}^{-1}$ (Trull et 385 al., 2008; Armstrong et al., 2009; McDonnell and Buesseler, 2010). We did not measure the 386 concentration of $C_{p}$, but predict that $C_{p}$ represents about $3 \%$ of cysteine and $45 \%$ of glutathione 387 amounts in the water, assuming the solid-dissolved phase distribution of thiols is similar to that 388 observed by Dupont et al. (2006). Because dissolved thiol concentrations near the surface were $3890.1-1 \mathrm{nM}$, a range for sinking fluxes of particulate thiols of $10^{-2}-20$ nmole $\mathrm{m}^{-2} \mathrm{~d}^{-1}$ seems 390 reasonable. Thus, to at least a first order estimate, mixing/diffusion would appear to be 391 responsible for most of the vertical dispersion of dissolved cysteine and glutathione.

392 If eddy diffusion is indeed the primary way in which thiols are moved vertically in the ocean, 393 then concentration profiles could be modeled by the following equation:

$$
C_{z}=C_{0} e^{-(\lambda / K)^{1 / 2} z}
$$


396 Where $C_{z}$ is the concentration (mole $\mathrm{m}^{-3}$ ) at depth $z(\mathrm{~m}), C_{0}$ is the concentration at the surface

397 (mole $\left.\mathrm{m}^{-3}\right), \lambda$ is the decay/uptake constant $\left(\mathrm{d}^{-1}\right)$, and $K\left(\mathrm{~m}^{2} \mathrm{~d}^{-1}\right)$ is the vertical eddy diffusivity 398 (Glover et al., 2011). The lifetime of thiols $(1 / \lambda)$ with respect to decay/uptake would therefore be 399 equal to:

$$
\frac{1}{\lambda}=\frac{z_{5 \%}^{2}}{8.97 K}
$$

401

402 where $z_{5 \%}$ is the depth at which thiol concentrations decrease to $5 \%$ of their 403 surface/maximum concentration. Given the vertical eddy diffusivities $(K)$ noted above and the 404 observation that $z_{5} \%$ is about $100 \mathrm{~m}$, the lifetime of thiols suggested by the vertical profiles are on 405 the order of a few days to a century, with the higher end apparently more reasonable based on 406 direct measurements of $K$ at these depths (Ledwell et al., 1993). Lifetimes of highly bioactive 407 compounds like cysteine and glutathione in excess of a few days are not likely, which suggests 408 that the simple model of production at the surface/chlorophyll max and diffusion downward is 409 not appropriate and sources of the thiols below the surface and/or chlorophyll max are needed. 410 Thus, cysteine and glutathione are probably being released and then either destroyed or taken 411 back up again throughout the upper $500 \mathrm{~m}$ of the ocean by heterotrophs, and not just by 412 phototrophs in the photic zone. This may be a partial explanation for why poor correlations were 413 observed between cysteine, glutathione, and Chl $a$ concentrations, overall. Interestingly, the 414 absence of measurable dissolved cysteine and glutathione below about $500 \mathrm{~m}$ suggests that either 415 heterotrophic microorganisms at these depths do not release these low-molecular weight thiols in 416 substantial amounts or that release rates are less than decay by some process. This could be the 
417 result of either the relatively low abundance of heterotrophic microorganisms at such depths, or 418 their relatively low metabolic activity.

419 One potential source of cysteine, other than exudation from primary producers, is the 420 breakdown of dissolved polypeptides. Keil and Kirchman (1999) reported concentrations of 421 dissolved combined amino acids (DCAA) in the northwest Atlantic Ocean ranging from 167 to $422810 \mathrm{nM}$ at a site comparable to our station 2011-4 with regard to proximity to the shelf. Because 423 cysteine typically represents $0.5-2 \%$ by mole of amino acids in typical biological tissue (e.g. 424 Miseta and Csutora, 2000), we would predict that the concentration of cysteine in the DCAA 425 pool might represent 0.8 to $16 \mathrm{nM}$. These predicted concentrations of cysteine are greater than 426 those we measured in the North Atlantic but suggest that protein-associated cysteine is a 427 potentially significant source of upon peptide degradation. Because this potential source of 428 cysteine is $10-100 \times$ more abundant than dissolved free cysteine, the breakdown of DCAAs could 429 explain cysteine concentrations in the ocean, as long as DCAAs degrade at a rate that is no more 430 than $\sim 100 \times$ slower than the cysteine uptake/degradation rate. Indeed, Keil and Kirchman (1999) 431 found that protein turnover times were, on average, about $30 \times$ longer than free amino acids (like 432 cysteine), which suggests that DCAA is a viable source of the dissolved cysteine we observed.

433 Glutathione is perhaps a bit more difficult to explain if its primary parent material is 434 phytochelatins. In the open ocean, phytochelatins have been observed at concentrations well 435 below that of glutathione (Ahner et al., 1998). This implies that either phytochelatin lifetimes are 436 short in the upper $500 \mathrm{~m}$ of the ocean or that release from cells is the primary source of 437 glutathione.

438 To be sure, the primitive modeling we have presented here is not intended to be a definitive 439 explanation for cysteine and glutathione distributions, but rather suggest some avenues for future 
440 research. It does appear from this initial approach that we can say that a model with only

441 production at either the surface or chlorophyll maximum is not adequate to explain the vertical

442 distribution of these thiols in the North Atlantic Ocean.

\section{5. Conclusions}

445 Our measurements of species-specific thiol concentrations during the U.S. GEOTRACES

446 North Atlantic zonal transect revealed that the thiol composition of the North Atlantic Ocean

447 appears to be quite different from that in the northeast Pacific Ocean, with only two low448 molecular weight thiols (cysteine and glutathione) being identified and detected. The vertical 449 profiles and surface horizontal gradient of both thiols exhibited near surface and coastal maxima, 450 often co-varying but not correlating with $\mathrm{Chl} a$, which is consistent with biological production by 451 phototrophs. However, the depth of thiol penetration down to $200-500 \mathrm{~m}$ suggests that 452 production at the surface is likely not the only source of these compounds, with either release by 453 heterotrophs or degradation of proteins and peptides within the mesopelagic zone the most likely 454 additional sources. The concentrations of cysteine and glutathione observed in the North Atlantic 455 Ocean discourage the view that they represent a significant fraction of complexing ligand classes 456 for $\mathrm{Cu}$ and $\mathrm{Zn}$, but are possibly important for less abundant chalcophiles such as $\mathrm{Cd}$ and $\mathrm{Hg}$.

\section{Acknowledgments}

459 We thank the captain and crew of the R/V Knorr, Katharina Pahnke and Chris Hayes for 460 sample collection and organization, and Rob Palomares and Susan Becker for additional support 461 on the ODF rosette. Colleen Hansel, Priya Ganguli, Matt McCarthy, and Tracy Mincer provided 
helpful discussions. This work was made possible by NSF grants OCE-0927274, -0928191, -

1132480, and -1132515 .

464

465

466

467

468

469

470

471

472

473

474

475

476

477

478

479

480

481

482

483

484

485

486

487

488

489

490

491

492

493

494

495

496

497

498

499

500

501

Ahner, B.A., Lee, J.G., Price, N.M., Morel, F.M.M., 1998. Phytochelatin concentrations in the equatorial Pacific. Deep-Sea Research Part I-Oceanographic Research Papers 45 (11), 1779-1796.

Ahner, B.A., Morel, F.M.M., 1995. Phytochelatin Production in Marine-Algae .2. Induction by Various Metals. Limnology and Oceanography 40 (4), 658-665.

Ahner, B.A., Morel, F.M.M., Moffett, J.W., 1997. Trace metal control of phytochelatin production in coastal waters. Limnology and Oceanography 42 (3), 601-608.

Ahner, B.A., Wei, L.P., Oleson, J.R., Ogura, N., 2002. Glutathione and other low molecular weight thiols in marine phytoplankton under metal stress. Marine Ecology Progress Series 232, 93-103.

Al-Farawati, R., van den Berg, C.M.G., 2001. Thiols in coastal waters of the western North Sea and English Channel. Environmental Science \& Technology 35 (10), 1902-1911.

Aristilde, L., Xu, Y., Morel, F.M.M., 2012. Weak Organic Ligands Enhance Zinc Uptake in Marine Phytoplankton. Environmental Science \& Technology 46 (10), 5438-5445.

Armstrong, R.A., Peterson, M.L., Lee, C., Wakeham, S.G., 2009. Settling velocity spectra and the ballast ratio hypothesis. Deep-Sea Research Part II-Topical Studies in Oceanography 56 (18), 1470-1478.

Baars, O., Abouchami, W., Galer, S.J.G., Boye, M., Croot, P., 2014. Dissolved cadmium in the Southern Ocean: Distribution, speciation, and relation to phosphate. Limnology and Oceanography 59 (2), 385-399.

Berthon, G., 1995. Critical evalution of the stability-constants of metal-complexes of aminoacids with polar side-chains. Pure and Applied Chemistry 67 (7), 1117-1240.

Bowman, K.L., Hammerschmidt, C.R., Lamborg, C.H., Swarr, G., 2015. Mercury in the North Atlantic Ocean: The U.S. GEOTRACES zonal and meridional sections. Deep Sea Research Part II: Topical Studies in Oceanography 116 (0), 251-261.

Bruland, K.W., 1992. Complexation of cadmium by natural organic-ligands in the central North Pacific. Limnology and Oceanography 37 (5), 1008-1017.

Bruland, K.W., Lohan, M.C., 2004. Controls of trace metals in seawater. In: Elderfield, H. (Ed.), Treatise on Geochemistry - Volume 6: The Oceans and Marine Geochemistry. Elsevier, Inc., New York, pp. 23-47.

Bruland, K.W., Rue, E.L., Smith, G.J., DiTullio, G.R., 2005. Iron, macronutrients and diatom blooms in the Peru upwelling regime: brown and blue waters of Peru. Marine Chemistry 93 (2-4), 81-103.

Buck, K.N., Bruland, K.W., 2005. Copper speciation in San Francisco Bay: A novel approach using multiple analytical windows. Marine Chemistry 96 (1-2), 185-198. 
Bundy, R.M., Barbeau, K.A., Buck, K.N., 2013. Sources of strong copper-binding ligands in Antarctic Peninsula surface waters. Deep-Sea Research Part II-Topical Studies in Oceanography 90, 134-146.

Chapman, C.S., Capodaglio, G., Turetta, C., van den Berg, C.M.G., 2009. Benthic fluxes of copper, complexing ligands and thiol compounds in shallow lagoon waters. Marine Environmental Research 67 (1), 17-24.

Chekmeneva, E., Gusmao, R., Manuel Diaz-Cruz, J., Arino, C., Esteban, M., 2011. From cysteine to longer chain thiols: thermodynamic analysis of cadmium binding by phytochelatins and their fragments. Metallomics 3 (8), 838-846.

Courbot, M., Diez, L., Ruotolo, R., Chalot, M., Leroy, P., 2004. Cadmium-responsive thiols in the ectomycorrhizal fungus Paxillus involutus. Applied and Environmental Microbiology 70 (12), 7413-7417.

Croot, P.L., Heller, M.I., 2012. The Importance of Kinetics and Redox in the Biogeochemical Cycling of Iron in the Surface Ocean. Frontiers in Microbiology 3, 219.

Dupont, C.L., Ahner, B.A., 2005. Effects of copper, cadmium, and zinc on the production and exudation of thiols by Emiliania huxleyi. Limnology and Oceanography 50 (2), 508-515.

Dupont, C.L., Goepfert, T.J., Lo, P., Wei, L.P., Ahnerz, B.A., 2004. Diurnal cycling of glutathione in marine phytoplankton: Field and culture studies. Limnology and Oceanography 49 (4), 991-996.

Dupont, C.L., Moffett, J.W., Bidigare, R.R., Ahner, B.A., 2006. Distributions of dissolved and particulate biogenic thiols in the subartic Pacific Ocean. Deep-Sea Research Part IOceanographic Research Papers 53 (12), 1961-1974.

Ellwood, M.J., Van den Berg, C.M.G., 2000. Zinc speciation in the Northeastern Atlantic Ocean. Marine Chemistry 68 (4), 295-306.

Ercal, N., Gurer-Orhan, H., Aykin-Burns, N., 2001. Toxic metals and oxidative stress part 1: mechanisms involved in metal-induced oxidative damage. Current Topics in Medicinal Chemistry 1, 529-539.

Fahey, R.C., Newton, G.L., Dorian, R., Kosower, E.M., 1980. Identification of Biological Thiols Using the Fluorescent Thiol Labeling Agent Monobromotrimethylammoniobimane. Federation Proceedings 39 (6), 1701-1701.

Fitzsimmons, J.N., Carrasco, G.G., Wu, J., Roshan, S., Hatta, M., Measures, C.I., Conway, T.M., John, S.G., Boyle, E.A., 2015. Partitioning of dissolved iron and iron isotopes into soluble and colloidal phases along the GA03 GEOTRACES North Atlantic Transect. Deep Sea Research Part II: Topical Studies in Oceanography 116 (0), 130-151.

Flock, O.R., Andreae, M.O., Drager, M., 1997. Environmentally relevant precursors of carbonyl sulfide in aquatic systems. Marine Chemistry 59 (1-2), 71-85.

Glover, D.M., Jenkins, W.J., Doney, S.C., 2011. Modeling Methods for Marine Science. Cambridge University Press, Cambridge, UK.

Hatta, M., Measures, C.I., Wu, J., Roshan, S., Fitzsimmons, J.N., Sedwick, P., Morton, P., 2015. An overview of dissolved Fe and Mn distributions during the 2010-2011 U.S. GEOTRACES north Atlantic cruises: GEOTRACES GA03. Deep Sea Research Part II: Topical Studies in Oceanography $116(0), 117-129$.

Heller, M.I., Croot, P.L., 2015. Copper speciation and distribution in the Atlantic sector of the Southern Ocean. Marine Chemistry 173 (0), 253-268.

Hsu-Kim, H., 2007. Stability of metal-glutathione complexes during oxidation by hydrogen peroxide and $\mathrm{Cu}(\mathrm{II})$-catalysis. Environmental Science \& Technology 41 (7), 2338-2342. 
Hu, H.Y., Mylon, S.E., Benoit, G., 2006. Distribution of the thiols glutathione and 3mercaptopropionic acid in Connecticut lakes. Limnology and Oceanography 51 (6), 2763-2774.

Jacquot, J.E., Moffett, J.W., 2015. Copper distribution and speciation across the International GEOTRACES Section GA03. Deep Sea Research Part II: Topical Studies in Oceanography $116(0), 187-207$.

Jenkins, W.J., Lott Iii, D.E., Longworth, B.E., Curtice, J.M., Cahill, K.L., 2015. The distributions of helium isotopes and tritium along the U.S. GEOTRACES North Atlantic sections (GEOTRACES GAO3). Deep Sea Research Part II: Topical Studies in Oceanography $116(0), 21-28$.

Kading, T., 2013. Distribution of Thiols in the Northwest Atlantic Ocean. Joint Program in Oceanography/Applied Ocean Science and Engineering (Massachusetts Institute of Technology; and the Woods Hole Oceanographic Institution).

Keil, R.G., Kirchman, D.L., 1999. Utilization of dissolved protein and amino acids in the northern Sargasso Sea. Aquatic Microbial Ecology 18 (3), 293-300.

Kiene, R.P., Linn, L.J., Gonzalez, J., Moran, M.A., Bruton, J.A., 1999. Dimethylsulfoniopropionate and methanethiol are important precursors of methionine and protein-sulfur in marine bacterioplankton. Applied and Environmental Microbiology 65 (10), 4549-4558.

Laglera, L.M., van den Berg, C.M.G., 2003. Copper complexation by thiol compounds in estuarine waters. Marine Chemistry 82 (1-2), 71-89.

Laglera, L.M., van den Berg, C.M.G., 2006. Photochemical oxidation of thiols and copper complexing ligands in estuarine waters. Marine Chemistry 101 (1-2), 130-140.

Lam, P.J., Ohnemus, D.C., Auro, M.E., 2015. Size-fractionated major particle composition and concentrations from the US GEOTRACES North Atlantic Zonal Transect. Deep Sea Research Part II: Topical Studies in Oceanography 116 (0), 303-320.

Lamborg, C.H., Fitzgerald, W.F., Skoog, A., Visscher, P.T., 2004. The abundance and source of mercury-binding organic ligands in Long Island Sound. Marine Chemistry 90, 151-163.

Leal, M.F.C., Van den Berg, C.M.G., 1998. Evidence for strong copper(I) complexation by organic ligands in seawater. Aquatic Geochemistry 4 (1), 49-75.

Ledwell, J.R., Watson, A.J., Law, C.S., 1993. Evidence for slow mixing across the pycnocline from an open-ocean tracer-release experiment. Nature 364 (6439), 701-703.

Lohan, M.C., Crawford, D.W., Purdie, D.A., Statham, P.J., 2005. Iron and zinc enrichments in the northeastern subarctic Pacific: Ligand production and zinc availability in response to phytoplankton growth. Limnology and Oceanography 50 (5), 1427-1437.

McDonnell, A.M.P., Buesseler, K.O., 2010. Variability in the average sinking velocity of marine particles. Limnology and Oceanography 55 (5), 2085-2096.

Measures, C., Hatta, M., Fitzsimmons, J., Morton, P., 2015. Dissolved Al in the zonal N Atlantic section of the US GEOTRACES 2010/2011 cruises and the importance of hydrothermal inputs. Deep Sea Research Part II: Topical Studies in Oceanography 116 (0), 176-186.

Miseta, A., Csutora, P., 2000. Relationship Between the Occurrence of Cysteine in Proteins and the Complexity of Organisms. Molecular Biology and Evolution 17 (8), 1232-1239.

Moffett, J.W., 1995. Temporal and Spatial Variability of Copper Complexation by Strong Chelators in the Sargasso-Sea. Deep-Sea Research Part I-Oceanographic Research Papers 42 (8), 1273-1295. 
Moingt, M., Bressac, M., Belanger, D., Amyot, M., 2010. Role of ultra-violet radiation, mercury and copper on the stability of dissolved glutathione in natural and artificial freshwater and saltwater. Chemosphere 80 (11), 1314-1320.

Mopper, K., Kieber, D.J., 1991. Distribution and biological turnover of dissolved organiccompounds in the water column of the Black Sea. Deep-Sea Research Part aOceanographic Research Papers 38, S1021-S1047.

Ndung'u, K., Ranville, M.A., Franks, R.P., Flegal, A.R., 2006. On-line determination of silver in natural waters by inductively-coupled plasma mass spectrometry: Influence of organic matter. Marine Chemistry 98 (2-4), 109-120.

Reeves, E.P., McDermott, J.M., Seewald, J.S., 2014. The origin of methanethiol in midocean ridge hydrothermal fluids. Proceedings of the National Academy of Sciences of the United States of America 111 (15), 5474-5479.

Rigo, A., Corazza, A., di Paolo, M.L., Rossetto, M., Ugolini, R., Scarpa, M., 2004. Interaction of copper with cysteine: stability of cuprous complexes and catalytic role of cupric ions in anaerobic thiol oxidation. Journal of Inorganic Biochemistry 98 (9), 1495-1501.

Rijstenbil, J.W., 2002. Assessment of oxidative stress in the planktonic diatom Thalassiosira pseudonana in response to UVA and UVB radiation. Journal of Plankton Research 24 (12), 1277-1288.

Rijstenbil, J.W., Gerringa, L.J.A., 2002. Interactions of algal ligands, metal complexation and availability, and cell responses of the diatom Ditylum brightwellii with a gradual increase in copper. Aquatic Toxicology 56 (2), 115-131.

Satoh, M., Hirachi, Y., Yoshioka, A., Kobayashi, M., Oyama, Y., 2002. Determination of cellular levels of nonprotein thiols in phytoplankton and their correlations with susceptibility to Mercury. Journal of Phycology 38 (5), 983-990.

Schaefer, J.K., Morel, F.M.M., 2009. High methylation rates of mercury bound to cysteine by Geobacter sulfurreducens. Nature Geosci 2 (2), 123-126.

Sedwick, P.N., Sohst, B.M., Ussher, S.J., Bowie, A.R., 2015. A zonal picture of the water column distribution of dissolved iron(II) during the U.S. GEOTRACES North Atlantic transect cruise (GEOTRACES GA03). Deep Sea Research Part II: Topical Studies in Oceanography $116(0), 166-175$.

Semeniuk, D.M., Bundy, R.M., Payne, C.D., Barbeau, K.A., Maldonado, M.T., 2015. Acquisition of organically complexed copper by marine phytoplankton and bacteria in the northeast subarctic Pacific Ocean. Marine Chemistry 173 (0), 222-233.

Sunda, W., Kieber, D.J., Kiene, R.P., Huntsman, S., 2002. An antioxidant function for DMSP and DMS in marine algae. Nature 418 (6895), 317-320.

Szczuka, A., Morel, F.M.M., Schaefer, J.K., 2015. The effect of thiols, zinc, and redox conditions on Hg uptake in Shewanella oneidensis. Environmental Science \& Technology.

Tang, D.G., Hung, C.C., Warnken, K.W., Santschi, P.H., 2000. The distribution of biogenic thiols in surface waters of Galveston Bay. Limnology and Oceanography 45 (6), 12891297.

Tang, D.G., Shafer, M.M., Vang, K., Karner, D.A., Armstrong, D.E., 2003. Determination of dissolved thiols using solid-phase extraction and liquid chromatographic determination of fluorescently derivatized thiolic compounds. Journal of Chromatography A 998 (1-2), 3140. 
Figure 4. Vertical profiles of cysteine (open triangles), glutathione (closed circles), oxygen

Tripp, H.J., Kitner, J.B., Schwalbach, M.S., Dacey, J.W.H., Wilhelm, L.J., Giovannoni, S.J., 2008. SAR 11 marine bacteria require exogenous reduced sulphur for growth. Nature 452 (7188), 741-744.

Trull, T.W., Bray, S.G., Buesseler, K.O., Lamborg, C.H., Manganini, S., Moy, C., Valdes, J., 2008. In situ measurement of mesopelagic particle sinking rates and the control of carbon transfer to the ocean interior during the Vertical Flux in the Global Ocean (VERTIGO) voyages in the North Pacific. Deep Sea Research Part II: Topical Studies in Oceanography 55 (14-15), 1684-1695.

Walsh, M.J., Ahner, B.A., 2013. Determination of stability constants of $\mathrm{Cu}$ (I), $\mathrm{Cd}$ (II) \& $\mathrm{Zn}$ (II) complexes with thiols using fluorescent probes. Journal of Inorganic Biochemistry 128, $112-123$.

Winterbourn, C.C., Metodiewa, D., 1999. Reactivity of biologically important thiol compounds with superoxide and hydrogen peroxide. Free Radical Biology and Medicine 27 (3-4), 322-328.

Figure legends

Figure 1. Sampling stations for the 2010 and 2011 legs of the US GEOTRACES North Atlantic Zonal Transect.

Figure 2. A typical chromatogram showing the retention times for some of the thiol species for which we had standards.

Figure 3. Vertical profiles of cysteine (open triangles), glutathione (closed circles), oxygen (black line) and Chlorophyll a fluorescence (gray line) at the stations occupied during the meridional component of the 2010 leg (from Lisbon to Cape Verde).

(black line) and Chlorophyll a fluorescence (gray line) at the stations occupied along the zonal Mauritanian Upwelling component of the 2010 leg. 
670 Figure 5. Vertical profiles of cysteine (open triangles), glutathione (closed circles), oxygen

671 (black line) and Chlorophyll a fluorescence (gray line) at the stations occupied along the zonal

672 western shelf break component of the 2011 leg (Woods Hole to Cape Verde).

673

674 Figure 6. Vertical profiles of cysteine (open triangles), glutathione (closed circles), oxygen

675 (black line) and Chlorophyll a fluorescence (gray line) at the stations occupied along the zonal

676 western North Atlantic basin component of the 2011 leg, including the Bermuda Atlantic Time

677 Series (BATS) station (station 10).

678

679 Figure 7. Vertical profiles of cysteine (open triangles), glutathione (closed circles), oxygen

680 (black line) and Chlorophyll a fluorescence (gray line) at the stations occupied along the zonal 681 eastern North Atlantic basin component of the 2011 leg, including the Mid-Atlantic Ridge TAG 682 site (station 16).

684 Figure 8. Surface water concentrations of cysteine and glutathione during the 2010 and 2011 legs 685 of the US GEOTRACES North Atlantic Zonal Transect. Concentrations for both species were 686 highest near the margins.

688 Figure 9. Temporal variation of surface water thiol concentrations as a function of the local time 689 when the samples were collected. The symbols are triangles for cysteine, squares for 690 glutathione, open for daylight collections, closed for night. 


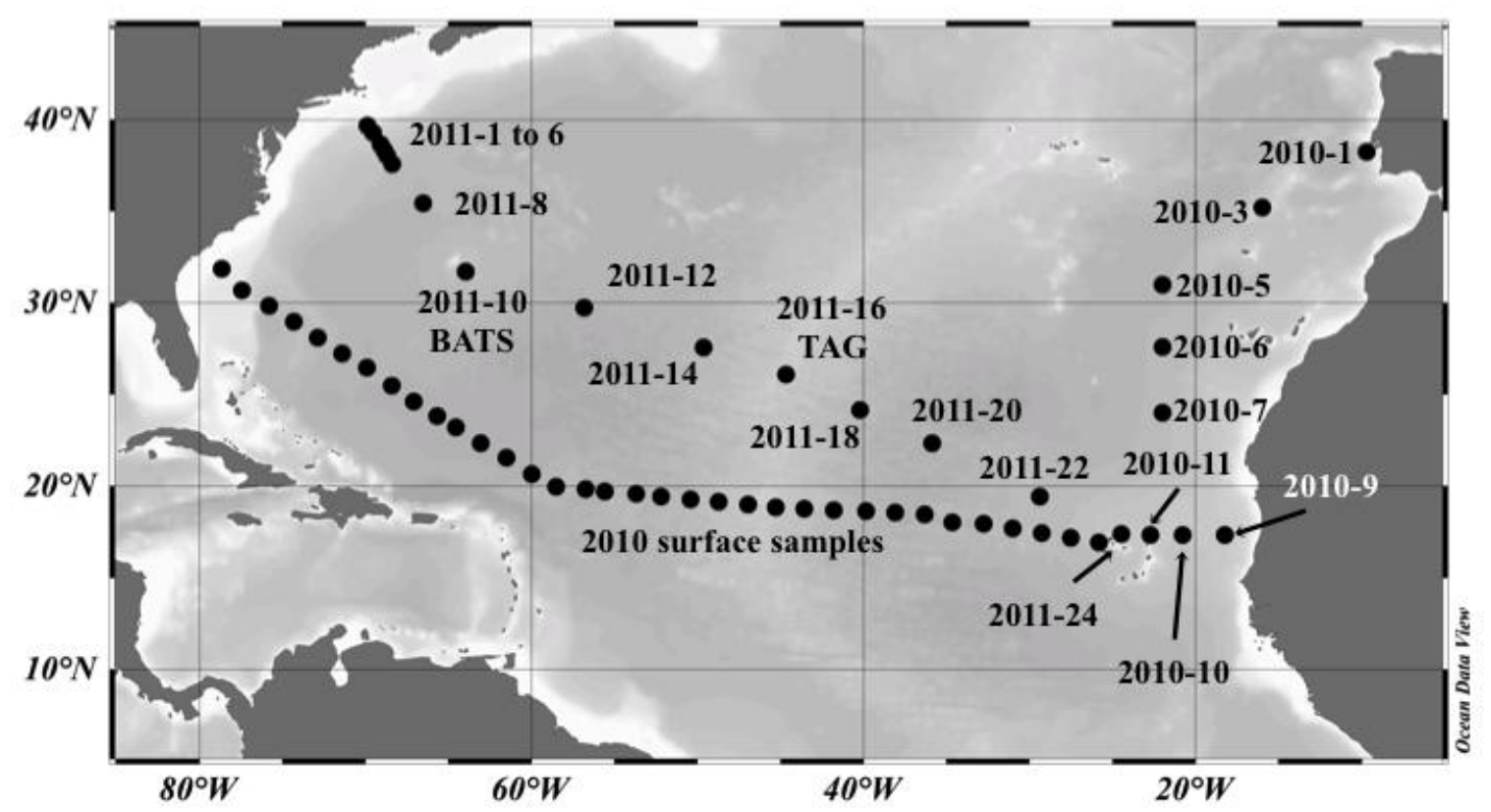

Figure 1 of 9 

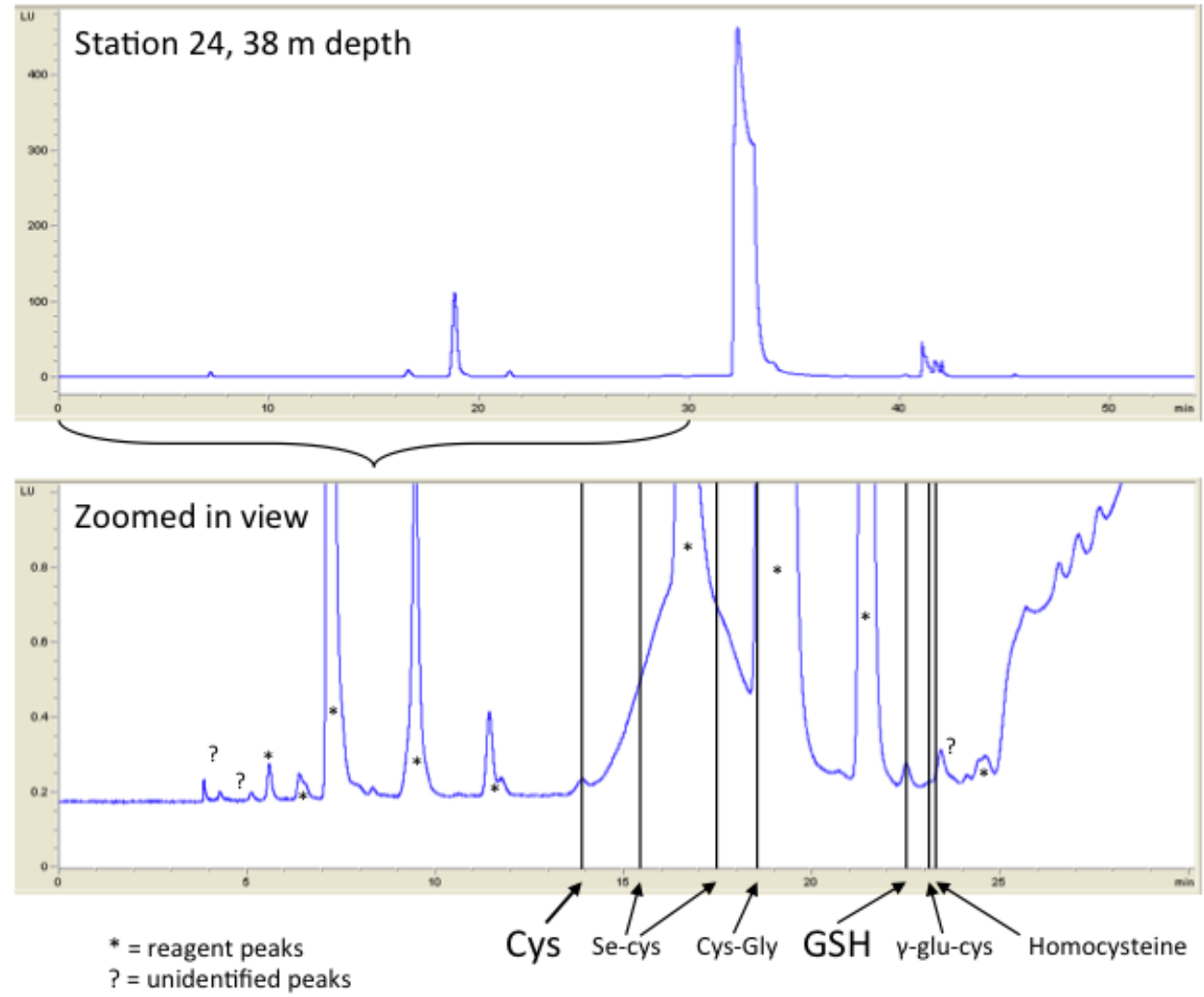

Figure 2 of 9 


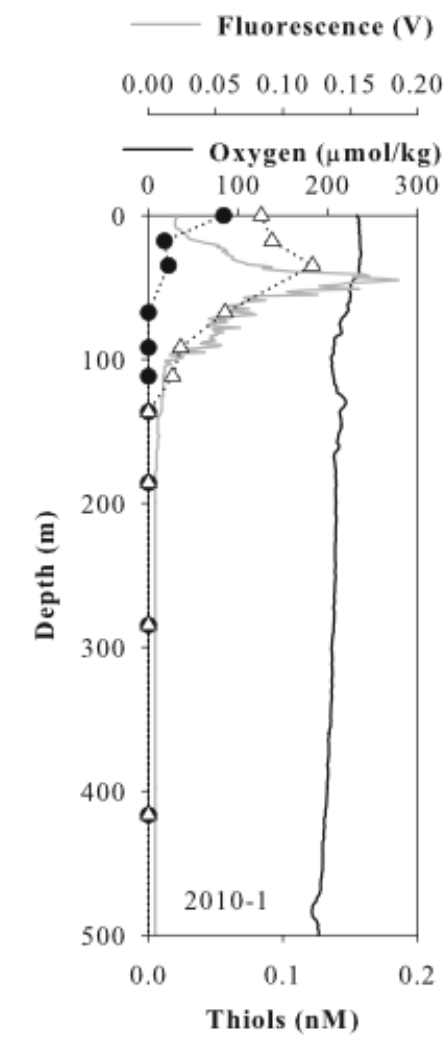

Fluorescence (V)

Fluorescence $(V)$

Fluorescence $(V)$ $\begin{array}{lllllllllllllll}0.00 & 0.05 & 0.10 & 0.15 & 0.20 & 0.00 & 0.05 & 0.10 & 0.15 & 0.20 & 0.00 & 0.05 & 0.10 & 0.15 & 0.20\end{array}$
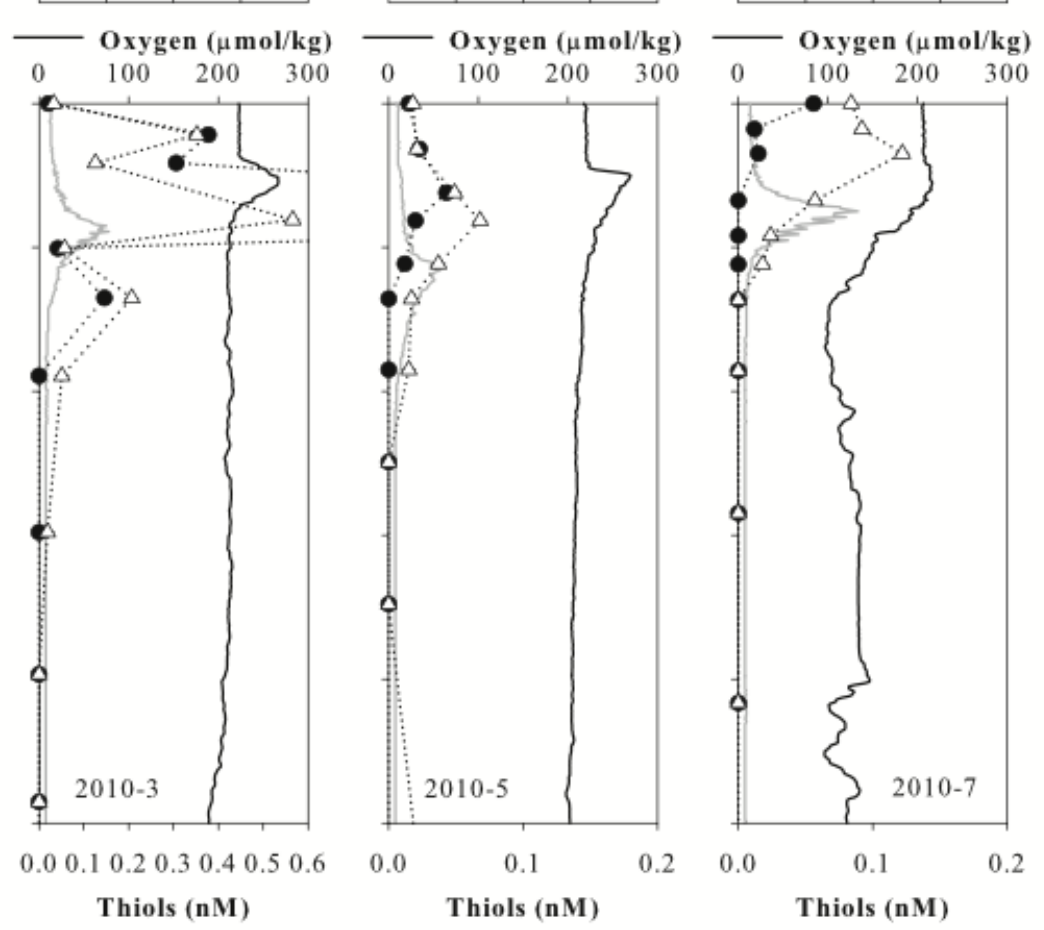

Figure 3 of 9 


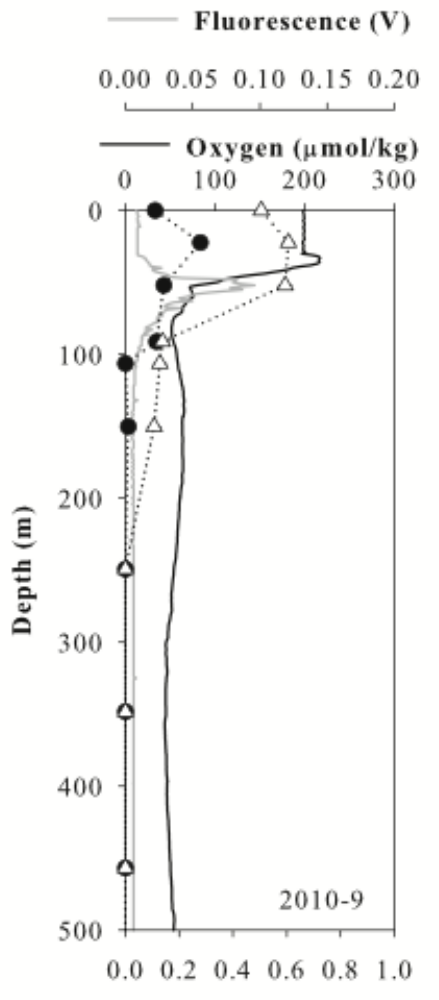

Thiols (nM)

\section{- Fluorescence (V)} $\begin{array}{llllll}0.00 & 0.05 & 0.10 & 0.15 & 0.20\end{array}$
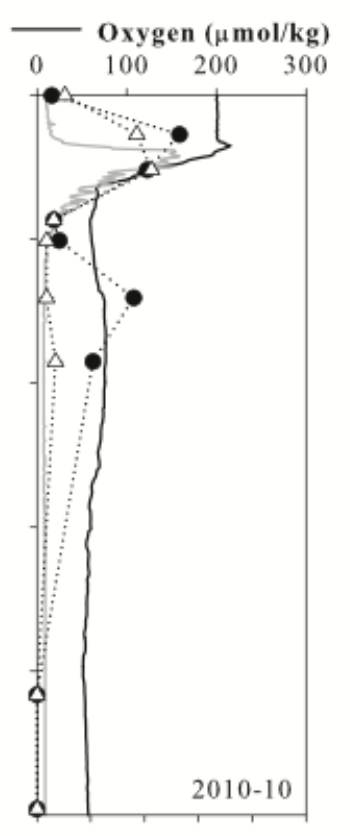

$\begin{array}{llllll}0.0 & 0.2 & 0.4 & 0.6 & 0.8 & 1.0\end{array}$ Thiols (nM)
Fluorescence (V) $\begin{array}{lllll}0.00 & 0.05 & 0.10 & 0.15 & 0.20\end{array}$

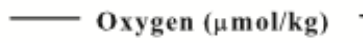
$\begin{array}{llll}0 & 100 \quad 200 \quad 300\end{array}$

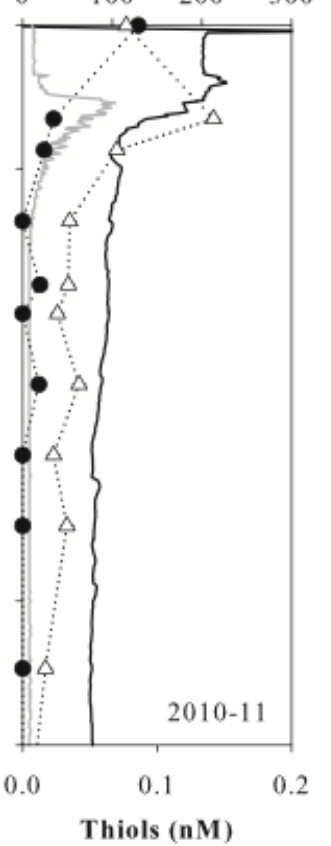

Fluorescence (V) $\begin{array}{lllll}0.0 & 0.1 & 0.2 & 0.3 & 0.4\end{array}$

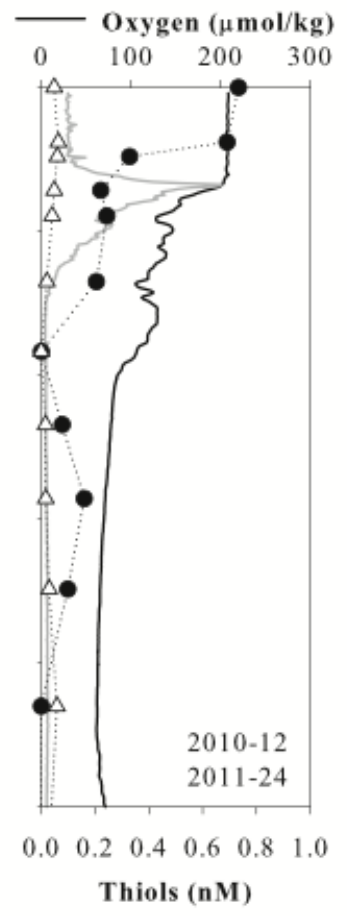

Figure 4 of 9 


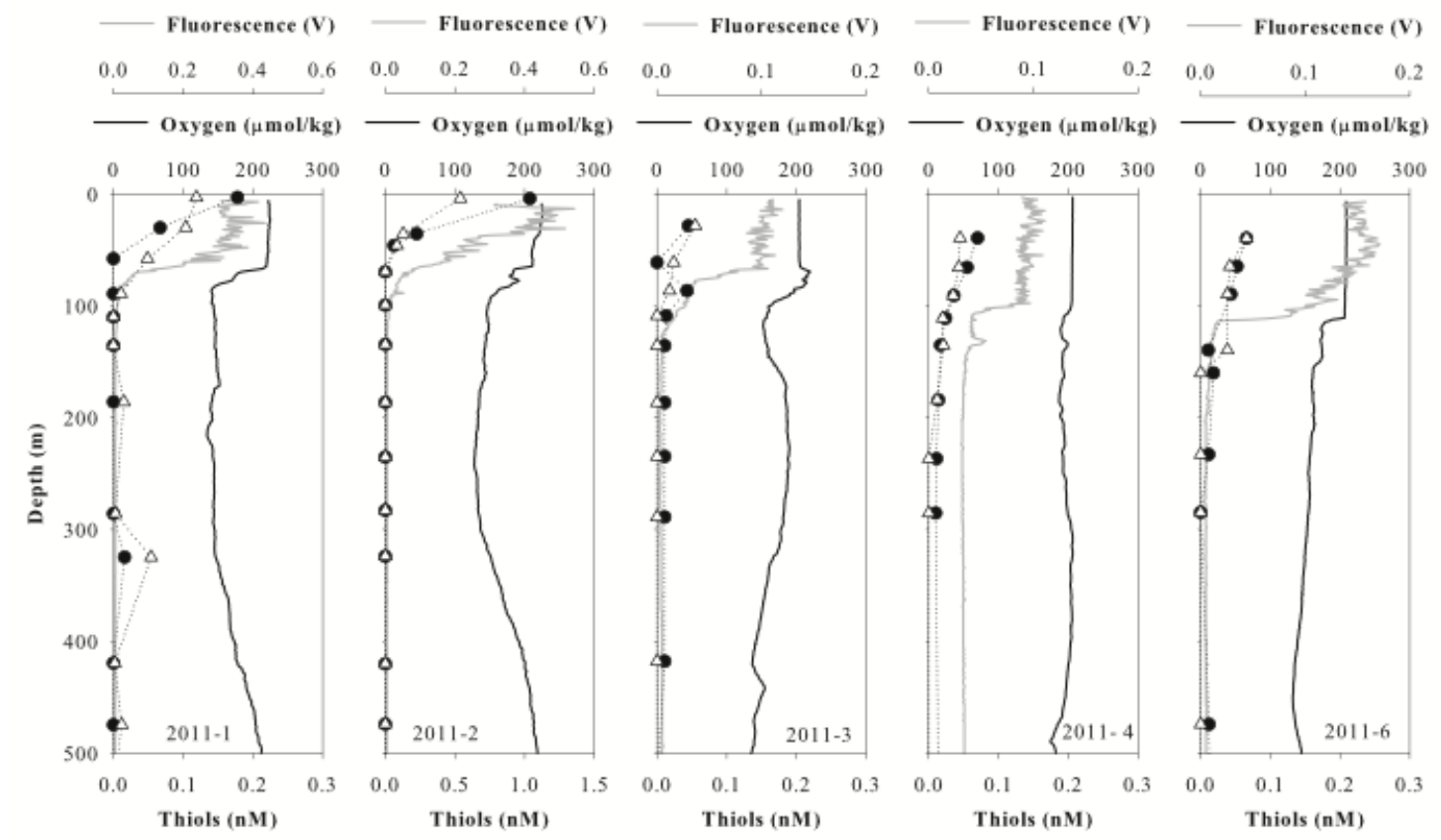

Figure 5 of 9 


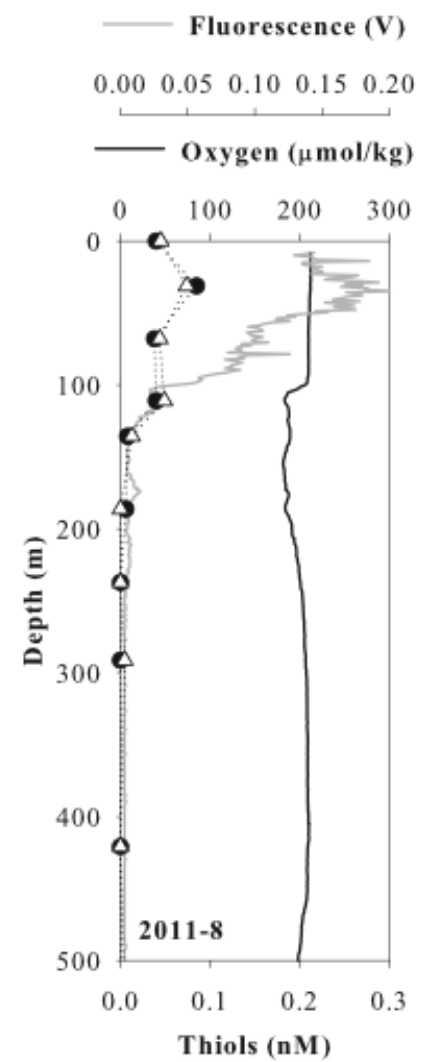

Fluorescence $(V)$

Fluorescence (V)

Fluorescence (V)

$\begin{array}{llllllllllllllll}0.00 & 0.05 & 0.10 & 0.15 & 0.20 & 0.00 & 0.05 & 0.10 & 0.15 & 0.20 & 0.00 & 0.05 & 0.10 & 0.15 & 0.20\end{array}$
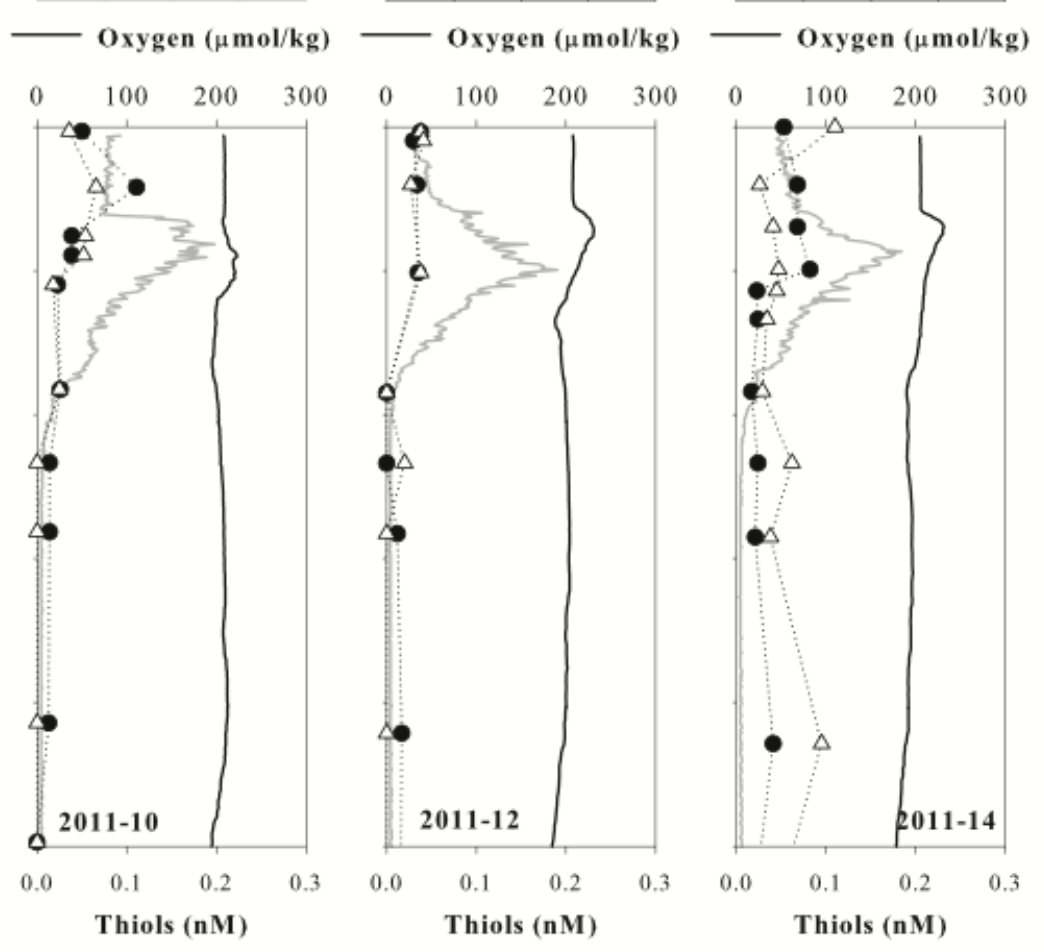

Figure 6 of 9 


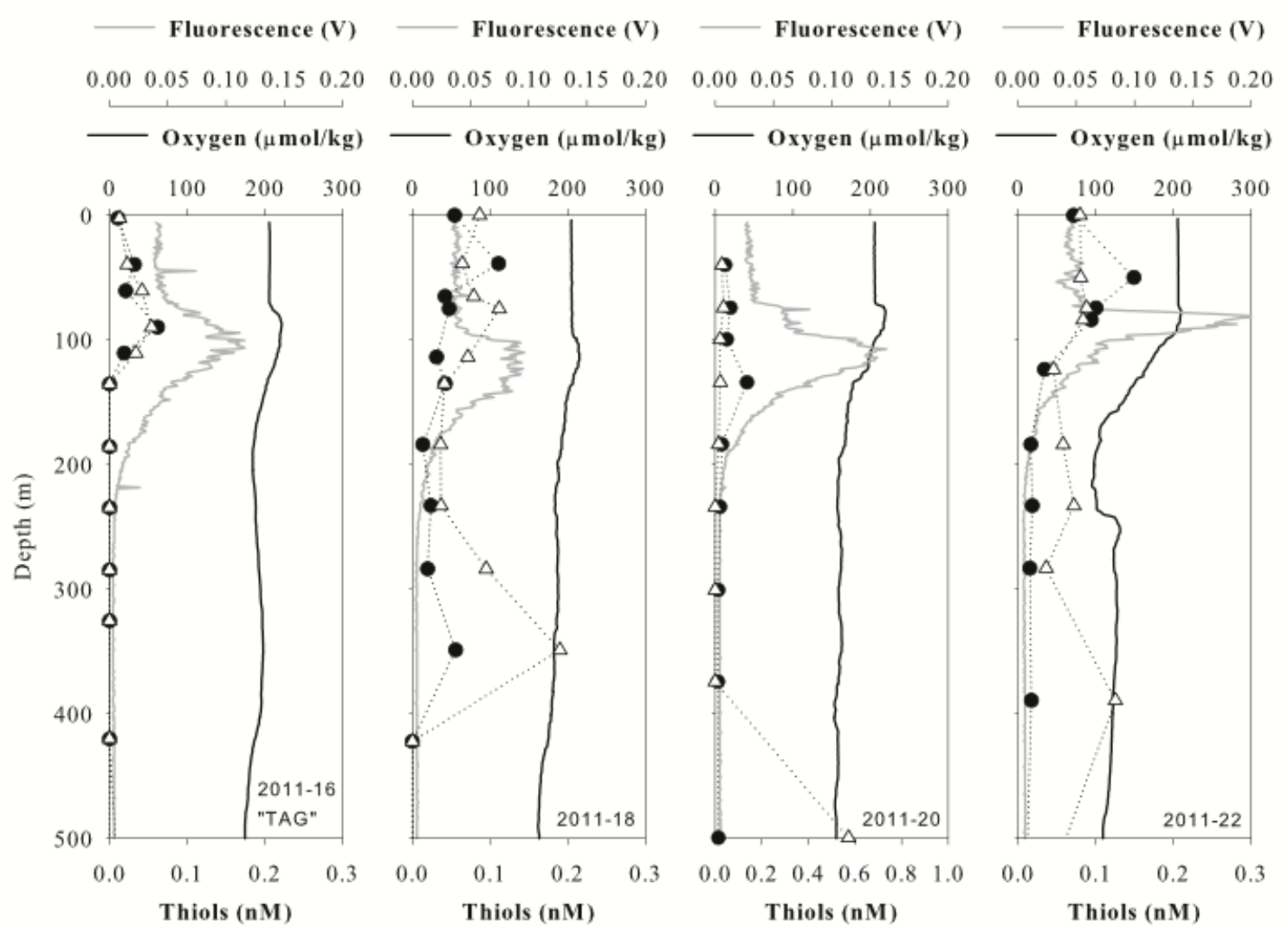

Figure 7 of 9 

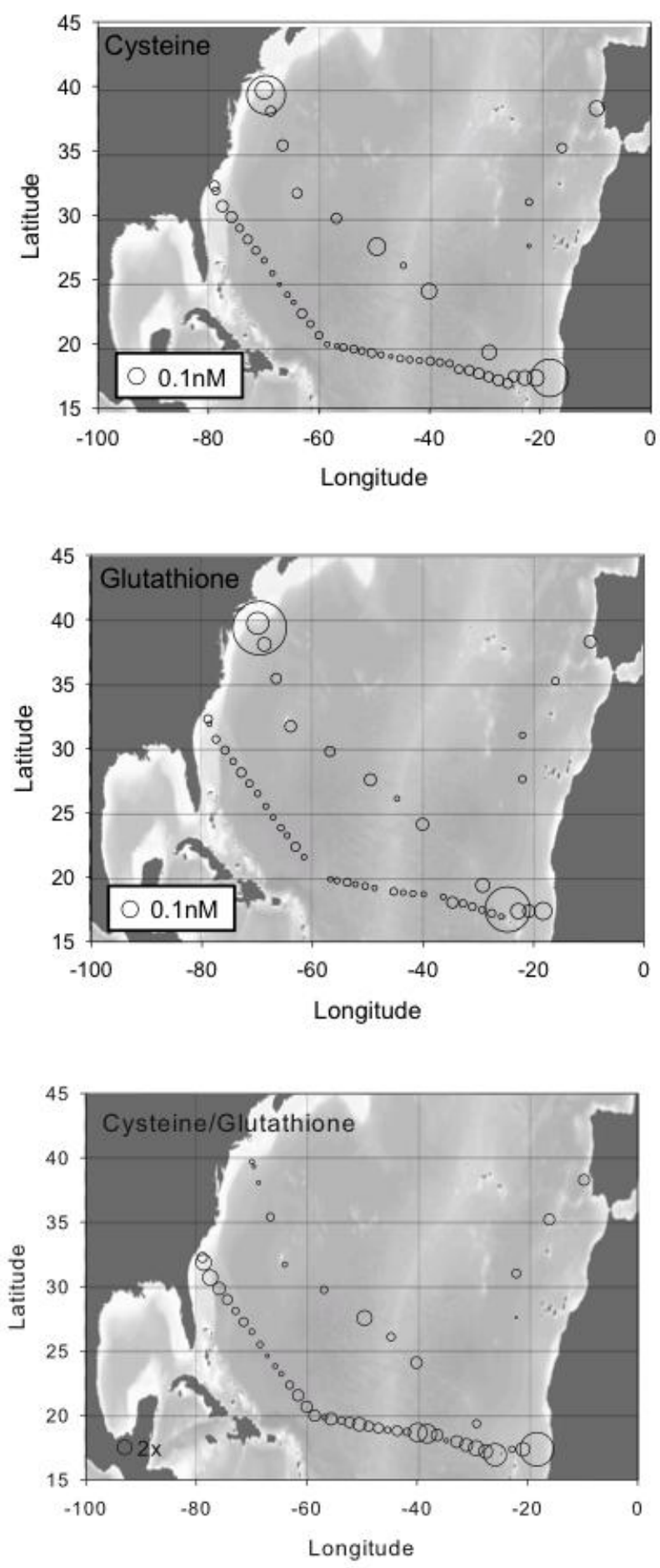

Figure 8 of 9 


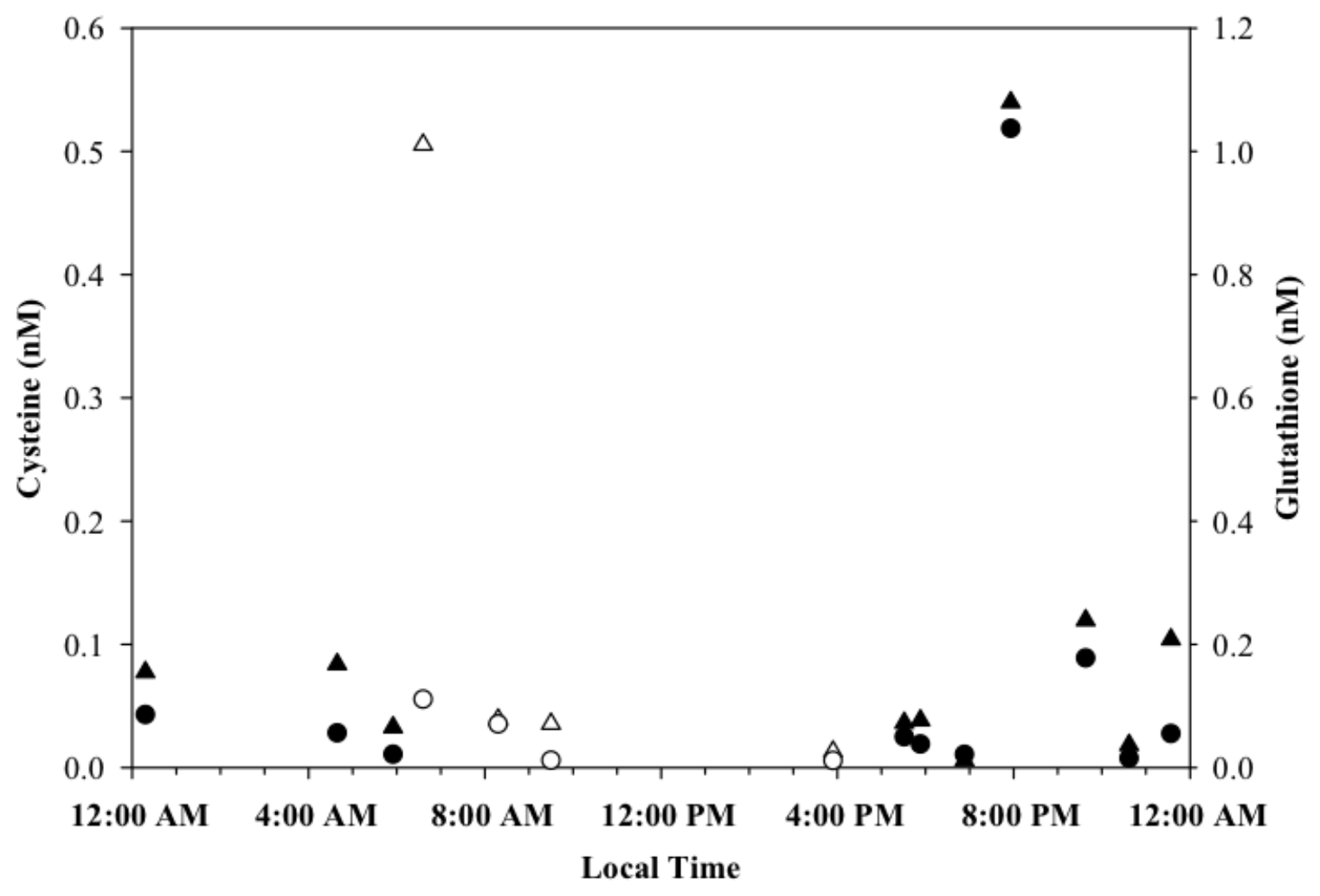

Figure 9 of 9 